\title{
Efeito da temperatura de descongelação na integridade de espermatozoides criopreservados de cães
}

[The effect of the thawing temperature on the integrity of canine cryopreserved sperm]

\author{
C.S. Moura ${ }^{1}$, A.K.S. Nunes ${ }^{2}$, B.S. Silva ${ }^{2}$, C.A. Peixoto ${ }^{2,3}$, A.R. Silva ${ }^{4}$, \\ S.V. Silva ${ }^{1,5}$, M.M.P. Guerra ${ }^{1 *}$ \\ ${ }^{1}$ ANDROLAB - Universidade Federal Rural de Pernambuco - Recife, PE \\ ${ }^{2}$ Centro de Pesquisa Aggeu Magalhães - FioCruz - Recife, PE \\ ${ }^{3}$ Centro de Tecnologias Estratégicas do Nordeste (CETENE) - Recife, PE \\ ${ }^{4}$ Universidade Federal Rural do Semi-Árido - Mossoró, RN \\ ${ }^{5}$ Centro de Biotecnologia - UFPB - João Pessoa, PB
}

\begin{abstract}
RESUMO
Avaliou-se a influência da temperatura de descongelação na integridade de espermatozoides criopreservados de cães. Foram utilizados reprodutores das raças Basset Hound $(n=3)$ e Rottweiler $(n=3)$, submetidos a colheitas de sêmen por manipulação peniana. As amostras de sêmen foram descongeladas a $37^{\circ} \mathrm{C} / 1 \mathrm{~min}(\mathrm{G} 1)$ ou $70^{\circ} \mathrm{C} / 6 \mathrm{~s}$ (G2) e avaliadas quanto à motilidade progressiva, vigor e integridade do acrossoma após 0,30 e 60 minutos de incubação $\left(37^{\circ} \mathrm{C}\right)$, e ultraestrutura espermática imediatamente após a descongelação. Em todos os tempos de incubação, a motilidade progressiva dos espermatozoides descongelados a $70^{\circ} \mathrm{C}$ por $6 \mathrm{~s}(74,6 \%)$ foi mais alta $(\mathrm{P}<0,05)$ que a dos descongelados a $37^{\circ} \mathrm{C}$ por $1 \mathrm{~min}(64,6 \%)$. O vigor espermático não diferiu $(\mathrm{P}>0,05)$ entre os grupos, e o porcentual de gametas com acrossomas íntegros foi maior $(\mathrm{P}<0,05)$ nos espermatozoides do $\mathrm{G} 1$ do que no G2. Lesões ultraestruturais foram identificadas nos espermatozoides descongelados de ambos os grupos, em maior quantidade nos gametas do G2. Conclui-se que amostras congeladas de sêmen de cães devam ser descongeladas a $37^{\circ} \mathrm{C}$ por $1 \mathrm{~min}$.
\end{abstract}

Palavras-chave: canino, criopreservação, danos espermáticos, ultraestrutura

\begin{abstract}
Aiming to evaluate the influence of the thawing temperature on the viability of canine cryopreserved sperm, Basset Hound $(n=3)$ and Rottweiler $(n=3)$ dogs were used, submitted to semen collected through manual manipulation. Semen samples were thawed at $37^{\circ} \mathrm{C}$ during $1 \mathrm{~min}(\mathrm{Gl})$ or at $70^{\circ} \mathrm{C}$ during $6 \mathrm{~s}(\mathrm{G} 2)$, and evaluated for progressive motility, vigor and acrosome integrity, after 0,30 e 60 minutes of incubation $\left(37^{\circ} \mathrm{C}\right)$, and sperm ultrastructure immediately after thawing. In all incubation times, the average of progressive motility was higher $(P<0.05)$ in samples from G2 Group (74.6\%) than from G1 $(64.6 \%)$. Sperm vigor had no difference $(P>0.05)$ between groups, and the percentage of gametes with intact acrosome was higher $(P<0.05)$ on sperm cells from $G 1$ than from G2. Ultrastructural changes were identified on dog sperm from both groups, and were observed in higher quantity in gametes from G2 Group. It can be concluded that samples of frozen dog sperm must be thawed at $37^{\circ} \mathrm{C}$ for Imin.
\end{abstract}

Keywords: canine, cryopreservation, sperm damage, ultrastructure

\section{INTRODUÇÃO}

A refrigeração e congelação do sêmen, bem como a inseminação artificial (IA), são biotécnicas utilizadas há bastante tempo nas espécies de interesse comercial. No entanto, na espécie canina, o uso de sêmen criopreservado na

Recebido em 14 de outubro de 2011

Aceito em 8 de outubro de 2012

*Autor para correspondência (corresponding author)

E-mail: mpguerra@dmv.ufrpe.br
IA ainda é limitado devido à baixa viabilidade espermática após a conservação (Flores et al., 2010). Dessa forma, estudos que aumentem a perspectiva de seu uso na criação de cães permitirão a troca de material genético de alto valor zootécnico entre localidades distantes, bem como o armazenamento desse material por períodos indefinidos (Linde-Forsberg e Forsberg, 1989). 
Os procedimentos de criopreservação espermática (diluição, refrigeração, congelação e descongelação) podem danificar esses gametas devido a mudanças de temperatura, estresse oxidativo, exposição aos efeitos tóxicos dos crioprotetores, assim como formação e dissolução de cristais de gelo no ambiente intra e extracelular (Medeiros et al., 2002). Por conseguinte, além dos componentes dos meios diluidores, do tipo de crioprotetor e do protocolo de congelação, o método de descongelação do sêmen constitui um fator importante para a preservação da integridade espermática (Farstad, 1996).

Estudos que utilizaram diferentes temperaturas e tempos de descongelação, como $35^{\circ} \mathrm{C}$ por $30 \mathrm{~s}$ (Olar et al., 1988), $37^{\circ} \mathrm{C}$ por $1 \mathrm{~min}$ (Silva et al., 1998; Moura et al., 1999), $50^{\circ} \mathrm{C}$ por 30s (Silva e Verstegen, 1995$), 70^{\circ} \mathrm{C}$ por 8 s (Peña et al., 2003) e $75^{\circ} \mathrm{C}$ por $12 \mathrm{~s}$ (Olar et al., 1988), apresentaram resultados contraditórios. Segundo IvanovaKicheva et al. (1995), a elevação da temperatura de descongelação reduz a ocorrência de dano osmótico às células espermáticas, além de prevenir a formação de cristais de gelo. No entanto, Farstad (1996) observou que a congelação rápida exige descongelação rápida, visando à manutenção da osmolaridade, do pH e do equilíbrio iônico das amostras de sêmen, assim como possibilita a rehidratação celular e previne os danos originários do crioprocessamento. Dessa forma, objetivou-se com este trabalho avaliar o efeito da temperatura de descongelação sobre a integridade de espermatozoides criopreservados de cães.

\section{MATERIAL E MÉTODOS}

Foram utilizados cães adultos das raças Basset Hound $(n=3)$ e Rottweiler $(n=3)$, vacinados e vermifugados, os quais foram mantidos em canis individuais e alimentados com ração comercial duas vezes ao dia, de acordo com o peso corporal $(10 \mathrm{~g} / \mathrm{kg}$ de PV), além de ser fornecida água ad libitum. Os animais considerados aptos à reprodução ao exame andrológico foram submetidos a quatro colheitas de sêmen por manipulação peniana a intervalo de três dias, totalizando 24 amostras de sêmen. Os ejaculados foram colhidos em tubos estéreis, e as frações foram separadas através das diferenças de coloração (translúcido ou branco leitoso) e da forma de ejaculação (jato ou gotejamento).
Inicialmente, a fração rica em espermatozoides foi avaliada (cor, volume e aspecto) e, a seguir, foi mantida em banho-maria $\left(37^{\circ} \mathrm{C}\right)$ durante a avaliação microscópica (motilidade progressiva, vigor, concentração, morfologia, integridade de acrossoma e ultraestrutura). Para análise da motilidade progressiva e do vigor espermático, uma alíquota $(10 \mu \mathrm{L})$ de cada ejaculado foi depositada sobre lâmina previamente aquecida a $37^{\circ} \mathrm{C}$ e conduzida ao microscópio óptico (Olympus, Tóquio, Japão), sendo submetidas à congelação as amostras que apresentaram motilidade progressiva $\geq 70 \%$ e vigor $\geq 3$. A concentração espermática foi avaliada em câmara de Neubauer, e os resultados, expressos em milhões de espermatozoides/mL, enquanto a análise morfológica das células espermáticas foi avaliada em câmara úmida.

Para análise da integridade do acrossoma, usouse a técnica de FITC-conjugada ao Peanut aglutinina (FITC-PNA; Roth et al., 1998), em que alíquotas $(10 \mu \mathrm{L})$ de sêmen foram depositadas e armazenadas a $4^{\circ} \mathrm{C}$, protegidas da luz. Após uma semana, as lâminas foram coradas com solução $(30 \mu \mathrm{L})$ de PNA $[20 \mu \mathrm{L}$ de PNA (Sigma, Saint Louis, MO, USA) $+480 \mu \mathrm{L}$ de $\mathrm{PBS}$ ] e refrigeradas $\left(4^{\circ} \mathrm{C}\right)$ durante $20 \mathrm{~min}$. A seguir, as lâminas foram imersas em $50 \mathrm{~mL}$ de PBS e colocadas dentro de caixa de isopor para secagem em temperatura ambiente. Após secagem, alíquotas de $5 \mu \mathrm{L}$ da solução UCD [5mg de Azida sódica; 0,5mL de PBS, 0,1 \% w/v de Fenilenediamina (Sigma, Saint Louis, MO, USA), 4,5mL de Glicerol; $\mathrm{pH} \mathrm{8,0]} \mathrm{foram}$ colocadas entre lâmina e lamínula e observadas em microscópio de fluorescência (Olympus, Tóquio, Japão), utilizando o filtro de fluoresceína (450-490nm, espelho dicromático de 510nm), onde foram contados 200 espermatozoides/lâmina e classificados em: a) acrossomas intactos (AI), quando a região acrossomal apresentava fluorescência verde; b) acrossomas reagidos (AR), quando apresentavam fluorescência verde na região equatorial da cabeça espermática ou não apresentavam fluorescência verde na cabeça.

Para avaliação de danos na ultraestrutura espermática, usou-se a microscopia eletrônica de transmissão (MET) (Burgess et al., 2001), em que as amostras do sêmen foram fixadas em glutaraldeído $(2 \%)+$ paraformaldeído $(2 \%)$ em tampão fosfato $(0,1 \mathrm{M})$. Em seguida, as amostras 
de sêmen foram pós-fixadas em ósmio + tampão fosfato, contrastadas em bloco com acetato de uranila (2,5\%), submetidas à desidratação crescente em acetona $(30, \%, 50 \%, 70 \%, 90 \%$ e $100 \%$ ) e incluídas em resina Epon (Sigma, Saint Louis, MO, USA). Foram realizados cortes ultrafinos em ultramicrótomo EM UC6 (Leica, Wetzlar, Germany) na velocidade de $2 \mathrm{~mm} / \mathrm{s}$ em corte de $70 \mathrm{~nm}$. Os cortes foram armazenados em grades e contrastados em acetato de uranila $(5 \%)$ por $1 \mathrm{~h} 15 \mathrm{~min}$ e citrato de chumbo por $4 \mathrm{~min}$, até o momento da fotodocumentação em microscópio eletrônico de transmissão (FEI Morgani 268D, 80-100Kv, Eindhoven, Netherlands).

Após determinação da concentração espermática, as amostras de sêmen fresco foram diluídas em $80 \%$ de Tris $[3,28 \mathrm{~g}$ de Tris (Sigma, Saint Louis, MO, USA); $1,78 \mathrm{~g}$ de ácido cítrico monohidratado; $1,25 \mathrm{~g}$ de D-frutose; q.s.p. $100 \mathrm{~mL} ; \mathrm{pH} 6,6], 20 \%$ de gema de ovo e $6 \%$ de glicerol. As amostras foram envasadas em palhetas, $0,25 \mathrm{~mL}$, na concentração de $100 \times 10^{6}$ espermatozoides, congeladas em máquina de congelação TK3000 (TK Tecnologia em congelação, Uberaba, MG, Brasil) utilizando a curva rápida $\left(0,5^{\circ} \mathrm{C} / \mathrm{min}\right.$ até $5^{\circ} \mathrm{C},-15^{\circ} \mathrm{C} / \mathrm{min}$ até $20^{\circ} \mathrm{C}$ e $-10^{\circ} \mathrm{C} / \mathrm{min}$ até $-120^{\circ} \mathrm{C}$ ), imersas em nitrogênio líquido $\left(-196^{\circ} \mathrm{C}\right)$ e armazenadas em botijão criobiológico. Uma semana após a congelação, as amostras foram descongeladas a $37^{\circ} \mathrm{C}$ por $1 \mathrm{~min}(\mathrm{G} 1)$ ou $70^{\circ} \mathrm{C}$ durante $6 \mathrm{~s}(\mathrm{G} 2) \mathrm{e}$, em seguida, submetidas ao teste de termoresistência (TTR) após 0,30 e 60min de incubação $\left(37^{\circ} \mathrm{C}\right)$, sendo avaliadas quanto à $\mathrm{MP}$, vigor e integridade do acrossoma, assim como ultraestrutura espermática imediatamente após a descongelação.

Os dados foram expressos na forma de média e desvio-padrão. Os resultados de MP e integridade acrossomal foram submetidos à transformação angular em arcoseno. No estudo de efeito dos tratamentos e raças sobre motilidade progressiva e integridade de acrossoma, utilizou-se a análise de variância (ANOVA), seguida do teste Tukey. Para a análise do vigor espermático, utilizou-se o teste de Mann-Whitney. Todos os testes foram realizados a $\mathrm{P}<0,05$, utilizando-se o programa Statview 5.0 ((SAS, 1998). Para avaliar a ultraestrutura dos espermatozoides obtidos de amostras in natura e descongelados em dois protocolos de descongelação $\left(37^{\circ} \mathrm{C}, 1 \mathrm{~min} ; 70^{\circ} \mathrm{C}\right.$, $6 s)$, utilizou-se análise descritiva.

\section{RESULTADOS}

As amostras de sêmen in natura obtidas dos cães apresentaram aspecto normal, coloração branca e aparência leitosa,

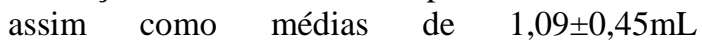
das frações ricas em espermatozoides, $328,13 \pm 51,64 \quad$ x $10^{6}$ espermatozoides $/ \mathrm{mL}$, $94,58 \pm 4,15 \%$ de motilidade progressiva, $4,92 \pm 0,28$ de vigor, $88,29 \pm 4,52 \%$ de espermatozoides morfologicamente normais e $97,42 \pm 1,77 \%$ de células com acrossomas intactos. $\mathrm{Na}$ análise das amostras de sêmen descongeladas e avaliadas após 0,30 ou $60 \mathrm{~min}$ de incubação a $37^{\circ} \mathrm{C}$ (Tab. 1), verificou-se maior $(\mathrm{P}<0,05)$ porcentual de células com motilidade progressiva no $\mathrm{G} 2\left(70^{\circ} \mathrm{C} ; 6 \mathrm{~s}\right)$ do que no $\mathrm{G} 1$ $\left(37^{\circ} \mathrm{C} ; 1 \mathrm{~min}\right)$. $\mathrm{O}$ vigor espermático não diferiu $(\mathrm{P}>0,05)$ entre grupos em todo o período de incubação. Os percentuais de espermatozoides com acrossomas íntegros das amostras de sêmen descongeladas a $37^{\circ} \mathrm{C}$ por $1 \mathrm{~min}$ foram maiores $(\mathrm{P}<0,05)$ do que nas descongeladas a $70^{\circ} \mathrm{C}$ por 6 s, após 0,30 ou $60 \mathrm{~min}$ de incubação a $37^{\circ} \mathrm{C}$.

A análise ultraestrutural dos espermatozoides obtidos de amostras in natura de sêmen constatou ondulações na membrana plasmática localizada na região da cabeça espermática e acrossomas íntegros (Fig. 1A). Cortes transversais (Fig. 1B) da cauda dos espermatozoides evidenciaram mitocôndrias e axonema preservados, enquanto os cortes longitudinais da peça intermediária (Fig. 1C) apresentaram preservação da membrana plasmática e das mitocôndrias. $\mathrm{Na}$ análise da ultraestrutura das amostras descongeladas de sêmen, foi possível identificar alterações tanto na cabeça quanto na cauda dos espermatozoides de amostras de G1 e G2 (Fig. 2A, 2B, 2C e 2D). Nas amostras do G1, observou-se ausência de membrana plasmática e acrossoma, com exposição da região equatorial (Fig. 1D), assim como vacuolização das mitocôndrias na peça intermediária (Fig. 1E e 1F). No entanto, ressalta-se que maior intensidade dos danos espermáticos foi observada nas células espermáticas descongeladas a $70^{\circ} \mathrm{C}(\mathrm{G} 2)$, em que se constataram ondulações e rupturas da membrana plasmática localizada na região da cabeça espermática, assim como células 
evidenciando ausência de acrossoma e edema da membrana acrossomal interna (Fig. 2A). Algumas células também evidenciaram no acrossoma ondulações, ruptura na membrana acrossomal externa e vesiculações indicativas de reação acrossomal (Fig. 2B). Na região da peça intermediária da cauda espermática, observou-se ondulação e ruptura da membrana plasmática, com desorganização, perda de material eletrodenso (Fig. 2C) e vacuolização mitocondrial, além de alteração na estrutura do axonema e da bainha fibrosa (Fig. 2D).

Tabela 1. Motilidade progressiva, vigor e integridade do acrossoma de espermatozoides descongelados de cães a $37^{\circ} \mathrm{C}$ por 1 minuto $(\mathrm{G} 1)$ e a $70^{\circ} \mathrm{C}$ por 6 segundos (G2), após 0,30 e 60 minutos de incubação a $37^{\circ} \mathrm{C}$

\begin{tabular}{ccccc}
\hline TI & Grupo & $\begin{array}{c}\text { MP } \\
(\%)\end{array}$ & $\begin{array}{c}\text { Vigor } \\
(0-5)\end{array}$ & $\begin{array}{c}\text { ACi } \\
(\%)\end{array}$ \\
\hline 0min & G1 & $64,58 \pm 13,51 \mathrm{~b}$ & $3,33 \pm 0,48$ & $81,83 \pm 6,72 \mathrm{a}$ \\
& $\mathrm{G} 2$ & $74,58 \pm 8,33 \mathrm{a}$ & $3,25 \pm 0,44$ & $69,88 \pm 21,32 \mathrm{~b}$ \\
& & & & \\
$30 \mathrm{~min}$ & $\mathrm{G} 1$ & $43,75 \pm 16,89 \mathrm{~b}$ & $2,46 \pm 0,51$ & $72,79 \pm 8,37 \mathrm{a}$ \\
& $\mathrm{G} 2$ & $53,33 \pm 13,41 \mathrm{a}$ & $2,92 \pm 0,28$ & $50,46 \pm 27,36 \mathrm{~b}$ \\
$60 \mathrm{~min}$ & & & & \\
& $\mathrm{G} 1$ & $26,25 \pm 17,65 \mathrm{~b}$ & $2,25 \pm 0,68$ & $60,63 \pm 18,22 \mathrm{a}$ \\
& $\mathrm{G} 2$ & $39,58 \pm 16,01 \mathrm{a}$ & $2,58 \pm 0,50$ & $39,54 \pm 22,99 \mathrm{~b}$ \\
\hline
\end{tabular}

$\mathrm{TI}=$ tempo de incubação; $\mathrm{MP}=$ motilidade progressiva; $\mathrm{ACi}=$ acrossomas íntegras. Letras minúsculas distintas na mesma coluna indicam diferença significativa $(\mathrm{P}<0,05)$ entre grupos experimentais em cada tempo de avaliação.

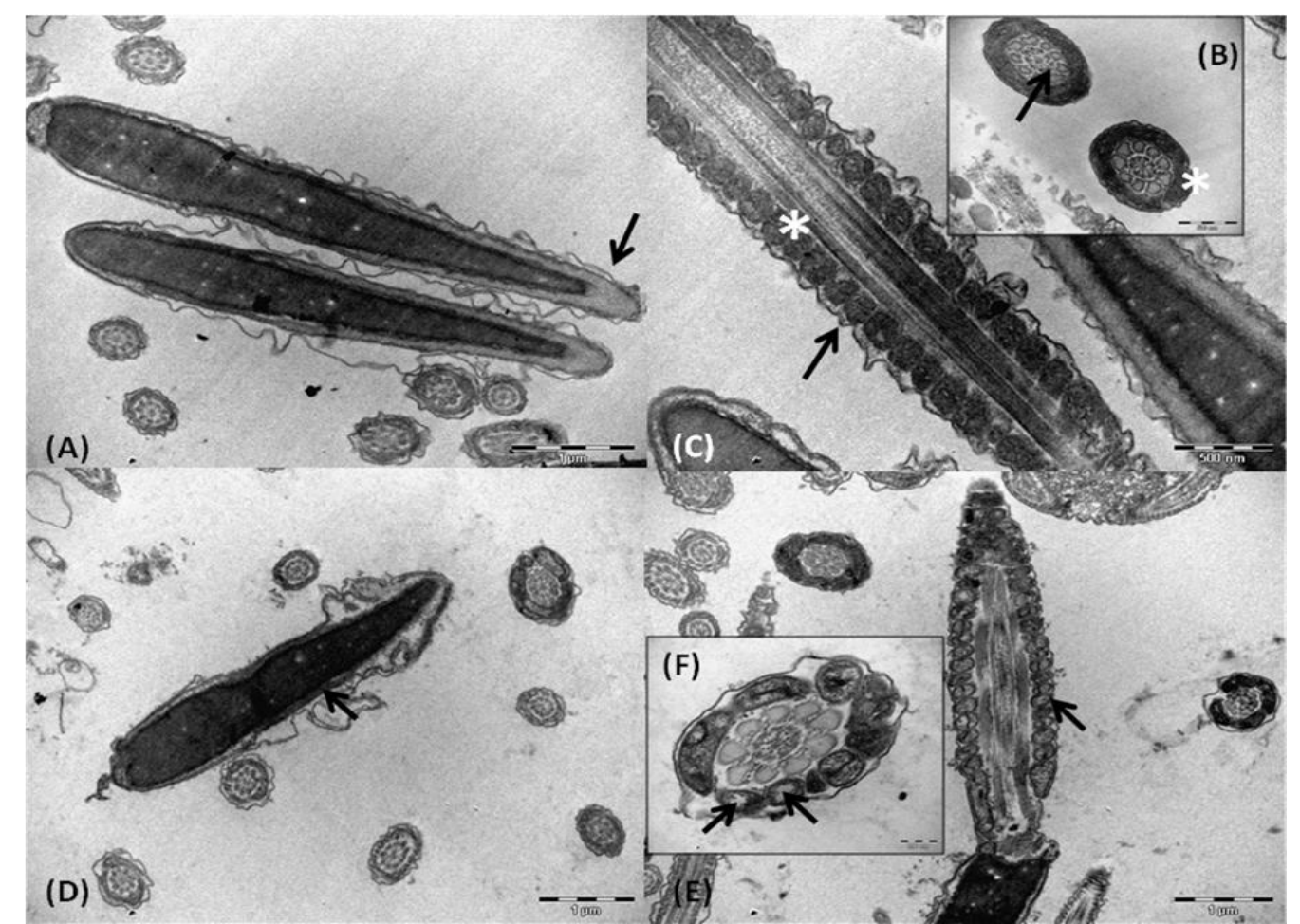

Figura 1. Análise ultraestrutural de espermatozoides in natura $\left(\mathrm{A}, \mathrm{B}\right.$ e C) e descongelados a $37^{\circ} \mathrm{C}$ por 1 minuto $(\mathrm{D}, \mathrm{E}$ e F), obtidos de cães das raças Basset Hound e Rottweiler. A: corte longitudinal da cabeça evidenciando ondulação da membrana plasmática e acrossoma íntegro (seta); B: corte transversal da peça intermediária apresentando mitocôndrias (asterisco) e axonema (seta) preservados; C: corte longitudinal da peça intermediária com preservação da membrana plasmática (seta) e mitocôndrias (asterisco); D: corte longitudinal da cabeça evidenciando ausência de membrana plasmática e acrossoma, com exposição da região equatorial (seta); E e F: corte longitudinal (E) e transversal (F) da peça intermediária apresentando vacuolização das mitocôndrias (setas). 


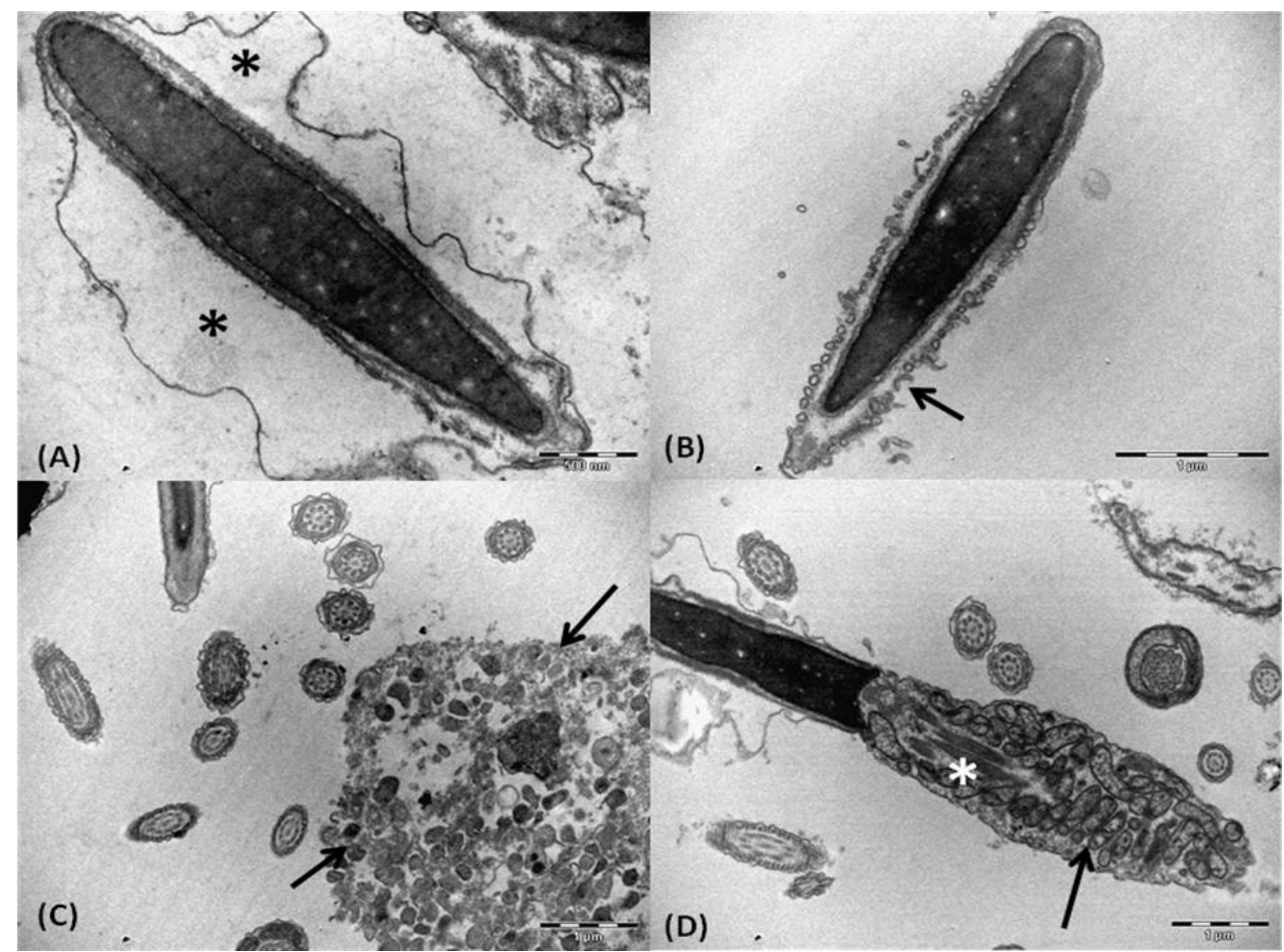

Figura 2. Análise ultraestrutural de espermatozoides descongelados a $70^{\circ} \mathrm{C}$ por 6 segundos, obtidos de cães das raças Basset Hound e Rottweiler. A: corte longitudinal da região da cabeça evidenciando ausência de acrossoma e edema da membrana acrossomal interna (asteriscos); B: corte longitudinal da região da cabeça apresentando vesiculações indicativas de reação acrossomal (seta); C: material eletrodenso resultante da desorganização da cauda (setas); D: corte longitudinal da cabeça e peça intermediária demonstrando vacuolização das mitocôndrias (seta) e desorganização da bainha fibrosa (asterisco).

\section{DISCUSSÃO}

Os elevados percentuais de espermatozoides com motilidade progressiva nas amostras descongeladas de sêmen em ambos os grupos devem-se provavelmente ao controle na redução da temperatura de congelação (Yu et al., 2002), determinado pelo uso do método automatizado (Coleto et al., 2006). No entanto, observou-se que a temperatura de descongelação exerceu efeito na motilidade progressiva das células espermáticas, uma vez que as amostras de sêmen descongeladas em temperatura mais elevada $\left(70^{\circ} \mathrm{C}\right.$ durante 6 s) apresentaram maior motilidade progressiva do que aquelas descongeladas em menor temperatura $\left(37^{\circ} \mathrm{C}\right.$ durante $1 \mathrm{~min}$ ) após 0,30 e $60 \mathrm{~min}$ de incubação a $37^{\circ} \mathrm{C}$. Esse resultado pode ser justificado pelo fato de a elevação da temperatura de descongelação reduzir os danos osmóticos nas células e prevenir a formação de cristais de gelo (Ivanova-Kicheva et al., 1995).
Os resultados de motilidade progressiva obtidos com as amostras descongeladas a $70^{\circ} \mathrm{C}$ durante 6s (G2) também foram descritos por Ström et al. (1997), utilizando o mesmo diluente e igual temperatura de descongelação para o sêmen de cães. Peña et al. (1998) relataram resultados inferiores utilizando o mesmo diluente $\mathrm{e}$ semelhante temperatura de descongelação $\left(75^{\circ} \mathrm{C}\right.$; $6 \mathrm{~s})$. Isso pode ser causado por diferenças genéticas na membrana celular desses gametas, resultando em diferencial na permeabilidade da membrana, com alterações no movimento da água e em formação de gelo intracelular, culminando em morte das células (Eilts, 2005). Por outro lado, a superioridade da motilidade progressiva das amostras do G2, quando comparadas às do $\mathrm{G} 1$, também foram descritas por Rota et al. (1998), ao relatarem que amostras congeladas com 5\% de glicerol e submetidas à taxa de descongelação rápida $\left(70^{\circ} \mathrm{C} ; 8 \mathrm{~s}\right)$ apresentaram grande percentual de gametas vivos durante a incubação a $37^{\circ} \mathrm{C}$. Os autores 
consideraram que os bons resultados da taxa de descongelação estavam relacionados à concentração ideal do crioprotetor no meio diluidor. Neste estudo, a ausência de diferença no vigor espermático das amostras descongeladas em ambas as temperaturas corrobora os resultados de Silva et al. (1998), ao relatarem que diferentes temperaturas de descongelação $\left(37^{\circ} \mathrm{C}\right.$ por $1 \mathrm{~min}$ ou $50^{\circ} \mathrm{C}$ por 30 s) não interferem no vigor dessas células espermáticas submetidas à incubação de $37^{\circ} \mathrm{C}$.

A redução dos percentuais de espermatozoides com acrossomas íntegros observados nas amostras de ambos os grupos, quando comparados àqueles das amostras in natura, se deve ao fato de o processo de congelação/descongelação provocar danos acrossomais irreversíveis à célula espermática, semelhantes aos observados após a capacitação espermática (Schembri et al., 2002). Todavia, os maiores percentuais de células com acrossomas íntegros das amostras do G1, quando comparados aos do G2, diferem dos relatos de Rota et al. (1998), ao observarem que amostras de sêmen congeladas com $5 \%$ de glicerol e descongeladas a $70^{\circ} \mathrm{C}$ durante $8 \mathrm{~s}$ apresentaram maior percentual de células com membrana plasmática intacta após $5 \mathrm{~h}$ de incubação a $38^{\circ} \mathrm{C}$. Peña et al. (1998) obtiveram menores porcentagens $(36,0 ; 25,6$ e $21,7 \%)$ de células com acrossomas íntegros após 0, 30 e 60min de incubação, respectivamente, após descongelação a $75^{\circ} \mathrm{C}$ por 6 segundos, semelhante àquela usada neste estudo. Os resultados deste estudo também diferem dos relatados por Ivanova-Kicheva et al. (1995), ao observarem que as amostras descongeladas a $55^{\circ} \mathrm{C}$ por $5 \mathrm{~s}$ apresentam menos lesões nos acrossomas do que aquelas descongeladas a $37^{\circ} \mathrm{C}$ por $8 \mathrm{~s}$, o que pode ser justificado pelo fato de esses autores terem usado temperatura menos elevada $\left(55^{\circ} \mathrm{C}\right)$ do que aquela deste estudo $\left(70^{\circ} \mathrm{C}\right)$. Ressalta-se ainda que a descongelação a $70^{\circ} \mathrm{C}$ causou mais danos à membrana acrossomal externa após congelação/descongelação e incubação $\left(37^{\circ} \mathrm{C}\right)$ por $60 \mathrm{~min}$, com resultados que não atendem às exigências descritas por Christiansen (1988) para uso na IA.

Ao realizar a análise conjunta de motilidade progressiva e integridade de acrossomas espermáticos, constatou-se que, apesar de as amostras do G1 terem evidenciado menores valores de motilidade progressiva do que as do $\mathrm{G} 2$, esses espermatozoides apresentaram, em todo o período de incubação, maiores percentuais de células com acrossomas íntegros. Evidenciouse, assim, que as análises de motilidade progressiva e vigor espermático não devem ser os únicos parâmetros de determinação da viabilidade espermáticas pós-descongelação.

A ocorrência de edema na membrana plasmática localizada na região da cabeça espermática e observada na análise ultraestrutural das amostras de sêmen in natura pode ser atribuída à utilização do glutaraldeído como substância fixadora (Chirineia et al., 2006). No entanto, as lesões nas membranas plasmáticas observadas tanto na cabeça quanto na cauda de espermatozoides criopreservados, caracterizadas como edema, ondulações, rupturas e vacuolizações, podem ser decorrentes do processo de criopreservação (Silva et al., 2009). Ressalta-se que as lesões acrossomais com perda do conteúdo e edemaciação do acrossoma, perda de material eletrodenso e vesiculação da membrana acrossomal, similares às descritas por Rodrígues-Martínez et al. (1993), evidenciam decréscimo na viabilidade espermática (Burgess et al., 2001). Todavia, maior intensidade de danos espermáticos observados nas células descongeladas a $70^{\circ} \mathrm{C}$ pode estar relacionada aos efeitos do choque térmico envolvidos na crioinjúria durante o processo de reaquecimento das células, no momento da descongelação. Com o aumento da temperatura, a membrana plasmática é submetida a rearranjos estruturais envolvendo lipídeos e proteínas, cuja extensão e natureza são controladas pela interação entre temperatura e efeito soluto durante o processo de congelação (Holt et al., 1992). Por conseguinte, o choque térmico pode ser manifestado pela ruptura da membrana acrossomal, conforme relataram Medeiros et al. (2002).

Segundo Niżański e Kuropka (2005) e Jurado et al. (2007), a alteração mais comum observada nos espermatozoides obtidos de cães e submetidos à descongelação é a falsa reação do acrossoma, caracterizada por edema, vesiculação da membrana acrossomal externa e da membrana plasmática, assim como perda completa do acrossoma. Resultados semelhantes foram observados neste estudo nas duas temperaturas de descongelação, porém com maior frequência e intensidade nas amostras do G2. Estes resultados 
diferem dos encontrados por Chirineia et al. (2006), ao descongelarem o sêmen a $70^{\circ} \mathrm{C}$ por $8 \mathrm{~s}$, e de Farstad (1996), ao observar que a congelação rápida exige descongelação rápida, visando à manutenção da osmolaridade, do pH e do equilíbrio iônico das amostras de sêmen, além de possibilitar a rehidratação e prevenção de danos celulares originários do crioprocessamento. Ao observar as avaliações em conjunto, observa-se que a descongelação a $70^{\circ} \mathrm{C}$ (6s) aumentou a ocorrência de falsa reação acrossomal, sendo evidenciada pela menor integridade acrossomal, maior alteração na ultraestrutura celular e maior percentual de gametas com movimento progressivo, caracterizando o fenômeno de hiperativação espermática.

Neste estudo, a avaliação qualitativa da ultraestrutura dos espermatozoides por meio da MET possibilitou identificar danos espermáticos que não seriam perceptíveis na análise por microscopia óptica (Silva et al., 2009). Assim, apesar de esse método não ser utilizado rotineiramente na avaliação do sêmen de cães, em virtude do custo elevado de processamento, ressalta-se a importância de sua utilização, visando predizer in vitro a viabilidade espermática in vivo, uma vez que não foi realizada IA utilizando amostras de sêmen descongeladas sob diferentes temperaturas. Além do fato de terem sido utilizadas várias técnicas de avaliação espermática pós-descongelação, considerado bom indicador de seu potencial fecundante.

\section{CONCLUSÃO}

De acordo com os resultados de integridade de acrossoma e ultraestrutura espermática, é possível concluir que a descongelação das amostras de sêmen de cão a $70^{\circ} \mathrm{C}$ por $6 \mathrm{~s}$ aumenta a ocorrência de danos espermáticos, sendo recomendada a descongelação a $37^{\circ} \mathrm{C}$ por 1 min.

\section{AGRADECIMENTOS}

À Tatiana Pagliane e sua equipe, por ceder os animais do canil Brave Basset Kennel para a realização deste experimento; à CAPES, pela concessão de bolsa de doutorado ao primeiro autor; e à FACEPE e ao $\mathrm{CNPq}$, pelo apoio financeiro.

\section{REFERÊNCIAS}

BURGESS, C.M.; BREDL, J.C.S.; PLUMMER, J.M. et al. Vital and ultrastructural changes in dog spermatozoa during cryopreservation. $J$. Reprod. Fertil., v.57, p.357-363, 2001.

CHIRINEIA, V.H.; MARTINS, M.I.M.; SOUZA, F.F. et al. Características morfofuncionais do sêmen canino refrigerado e congelado, usando dois diferentes meios diluentes. Cienc. Anim. Bras., v.7, p.407-415, 2006.

CHRISTIANSEN, J. Reprodução no cão e no gato. São Paulo: Manole, 1988. 362p.

COLETO, Z.F.; SOUZA, A.F.; SILVA, E.C.B. et al. Efeito da adição de vitamina $\mathrm{C}$ e Trolox na viabilidade de espermatozoides criopreservados de cães, utilizando duas curvas de congelação. Supl. Rev. Cienc. Agrár., Belém, n.43, jun/jul. 2005. 1 CD_ROM.

EILTS, B.E. Theoretical aspects of canine semen cryopreservation. Theriogenology, v. 64, p.685$691,2005$.

FARSTAD, W. Semen cryopreservation in dog and foxes. Anim. Reprod. Sci., v.12, p.145-150, 1996.

FLORES, A.J.; FERNÁNDEZ, A.V.; HUAMÁN, U.H. et al. Refrigeración de semen canino utilizando glucosa, fructosa, trehalosa o sacarosa para prolongar la supervivencia espermática. Rev. Inv. Vet. Peru, v.21, p.26-34, 2010.

HOLT, W.V.; HEAD, M.F.; NORTH, R.D. Freeze-induced membrane damage in ram spermatozoa is manifested after thawing observations with experimental cryomicroscopy. Biol. Reprod., v.46, p.1086-1094, 1992.

IVANOVA-KICHEVA，M.G.; SUBEV，M.S.; BOBADOV, N.D. et al. Effect oh thawing regiments on the morphofunctional state of canine spermatozoa. Theriogenology, v.44, p.563-569, 1995.

JURADO, S.; SARMIENTO, P.; STORNELLI, A. Ultrastructural analysis of fresh and frozenthawed dog spermatozoa. Disponível em: https:// www.ciasem2005.cigb.edu.cu. Acesso em: 26 de julho de 2007. 
LINDE-FORSBERG， C.; FORSBERG， M. Fertility in dogs in relation to sêmen quality and the time and site of insemination. J. Reprod. Fertil., v.39, suppl., p.299-310, 1989.

MEDEIROS, C.M.O.; FORELL, F.; OLIVEIRA, A.T.D. et al. Current status of sperm cryopreservation: why isn't it better? Theriogenology, v.57, p.327-344, 2002.

MOURA, C.S.; CAVALCANTI, M.C.O.; GUERRA, M.M.P. et al. Cryopreservation of canine semen using different methods of refrigeration. Rev. Bras. Reprod. Anim., v.23, p.304-306, 1999.

NIZÁNSKI, W.; KUROPKA, P. Ultrastructural changes in dog spermatozoa after freezingthawing of semen extended in tris-based diluent supplemented with Equex STM. Eletr. J. Polish Agric. Univ., v.8, 2005. Disponível em: <www.ejpau.media.pl/volume8/issue4/art54.html>. Acesso em: 21.03.2010.

OLAR, T.T.; BOWEN, R.A.; PICKETT, B.W. Influence of extender, cryopreservative and seminal processing procedures of postthaw motility of canine spermatozoa frozen in straws. Theriogenology, v.31, p.451-461, 1988.

PEÑA, A.I.; BARRIO, F.; QUINTELA, L.A. et al. Effect of different glycerol treatments on frozen-thawed dog sperm longevity and acrosomal integrity. Theriogenology, v.50, p.163-174, 1998.

PEÑA, F.J.; JOHANNISSON, A.; WALLGREN, M. et al. Antioxidant supplementation in vitro improves boar sperm motility and mitochondrial membrane potential after cryopreservation of different fractions of the ejaculate. Anim. Reprod. Sci., v.78, p.85-98, 2003.

RODRÍGUEZ-MARTÍNEZ, H.; EKWALL, H.; LINDE-FORSBERG, C. Fine structure and elemental composition of fresh and frozen dog spermatozoa. J. Reprod. Fertil., v.47, suppl., p.279-285, 1993.
ROTA, A.; LINDE-FORSBERG, C.; VANNOZZI, J. et al. Cryosurvival of dogs spermatozoa at different glycerol concentrations and freezing/thawing rates. Reprod. Dom. Anim., v.33, p.355-361, 1998.

ROTH, T.L.; WEISS, R.B.; BUFF, J.L. et al. Heterologous in vitro fertilization and sperm capacitation in an endangered African antelope, the Scimitar-Horned Oryx (Oryx dammah). Biol. Reprod., v.58, p.475-482, 1998.

SCHEMBRI, M.A.; MAJOR, D.A.; SUTTIE, J.J. et al. Capacitation-like changes in equine spermatozoa throughout the cryopreservation process. Reprod. Fertil. Dev., v.14, p.225-233, 2002.

SILVA, L.D.M.; VERSTEGEN, J. Comparisons between three different extenders for canine intrauterine insemination with frozen thawed spermatozoa. Theriogenology, v.44, p.571-579, 1995.

SILVA, A.R.; CARDOSO, R.C.S.; SILVA, L.D.M. Efeito do processo de descongelação sobre a viabilidade do sêmen canino in vitro. Cienc. Anim., v.8, p.75-80, 1998.

SILVA, A.R.; FONTENELE-NETO, J.D.; CARDOSO, R.C.S. et al. Description of ultrastructural damages in frozen-thawed canine spermatozoa. Cienc. Anim. Bras., v.10, p.595601, 2009.

STATVIEW. Version 5.0. statview reference. Cary: SAS Institute, 1998. 528p.

STRÖM, B.; ROTA, A.; LINDE-FORSBERG, C. In vitro characteristics of canine spermatozoa subjected to two methods of cryopreservation. Theriogenology, v.48, p.247-256, 1997.

YU, I.; SONGSANSSEN, N.; GODKE, R.A. et al. Differences among dogs in response of their spermatozoa to cryopreservation using various cooling and warming rates. Cryobiology, v.44, p.62-78, 2002. 